\title{
Screening and molecular characterization of cholesterol-lowering lactic acid bacteria isolated from African oil palm wine (Elaeis guineensis) and corn beer.
}

\section{Betrand Tatsinkou Fossi ( $\nabla$ tatsinkoufossi@yahoo.fr)}

Faculty of Science, University of Buea https://orcid.org/0000-0003-2320-7496

Dickson Ebwelle Ekabe

University of Buea

\section{Laure Toukam}

Department of Microbiology and Parasitology, University of Buea

\section{Henri Olivier Tatsilong}

Department of Microbiology and Parasitology, University of Buea

\section{Anandine Gagneux-Brunon}

University of Saint Etienne

\section{Celine Nkenfou}

Chantal Biya International Reference Centre for HIV/AIDS Research on Prevention and Treatment:

CIRCB, University of Yaounde I

\section{Bienvenu Bongue}

University of Saint Etienne

Research article

Keywords: Probiotics, cholesterol lowering activity, cardiovascular diseases, lactic acid bacteria, molecular identification.

Posted Date: November 13th, 2020

DOl: https://doi.org/10.21203/rs.3.rs-106340/v1

License: (1) This work is licensed under a Creative Commons Attribution 4.0 International License. Read Full License 


\section{Abstract}

Background: High serum cholesterol is a risk factor for cardiovascular disease (CVD), leading to many fatalities. Probiotic supplementation improves health benefits by lowering serum cholesterol. African oil palm (Elaeis guineensis) wine and corn beer have been described as potential sources of probiotic bacteria, but their cholesterol lowering activity has not been extensively investigated. Therefore in this study, we isolated and characterized lactic acid bacteria with probiotic and cholesterol lowering properties from these sources.

Methods: A total of fifty lactic acid bacteria (LAB) were isolated from palm wine and corn beer using de Man Rogosa and Sharpe (MRS) agar by pour plate method. Catalase negative and Gram positive colonies were considered as presumptive LAB. For probiotic properties and selection, acid and bile salt tolerance were evaluated based on viable colony count on MRS agar and cholesterol assimilation from culture media was performed by spectrophotometry. The data analysis was performed by One Way Analysis of Variance and $p$ value $<0.05$ was considered significant. The isolates with excellent cholesterol assimilation properties were selected and identified with species of morphology and biochemical analysis using API $50 \mathrm{CHL}$ kit and genotypic identification by sequencing of $16 \mathrm{~S}$ rRNA gene.

Results: Fifty isolates had morphological features similar to LAB. They were catalase negative and Gram positive colonies. Among the fifty isolates, five were considered as acid and bile tolerant (viable count exceeded $6 \log \mathrm{CFU} / \mathrm{ml})$, with two isolates having excellent cholesterol assimilation property $(>80 \%)$. The result obtained using API $50 \mathrm{CHL}$ kit did not agree with the genotypic identification which was used to confirm the identity of the isolates as most closely related to Lactobacillus brevis ATCC (Accession No.NR116238) and Enterococcus faeccium NBRC (Accession No. NR113904).

Conclusions: The two strains isolated from traditionally fermented drinks in Buea can be considered as potential probiotics. They can therefore be used to formulate food supplement needed to lower cholesterol in hypercholesterolemia patients.

\section{Background}

Cholesterol is a naturally occurring substance in the human body that plays vital roles in cell wall biosynthesis and hormone production. The liver and the intestinal mucosa are capable of synthesizing about $80 \%$ of de novo (endogenous) cholesterol needed in the body [1], requiring a small amount (20\%) of dietary (exogenous) cholesterol. However, when dietary cholesterol becomes higher, it can lead to a condition known as hypercholesterolemia (elevated blood cholesterol). This causes the accumulation of cholesterol deposits in blood vessels, leading to blockage or narrowing of arteries which supply blood to vital organs like the heart and brain. Hypercholesterolemia is the major risk factor for cardiovascular diseases (CVD) [2]. It has been predicted to remain the single leading cause of death for the next ten years, killing approximately 23.6 million people [3]. More than $80 \%$ of CDV deaths occur in low and 
middle-income countries, affecting men and women at the same rates [4]. A recent study carried out in Cameroon showed that deaths related to CDV (in-hospital case-fatality) were 15.8\% [5].

The use of low-fat diet so far is the most effective means of lowering elevated serum cholesterol [6]. This remedy however has limitations due to the unavailability of such diets and compliance of the consumer [7]. Probiotic bacteria appear as the most promising alternative. They are living organisms that confer a health benefit to the host when administered in adequate amount [8]. Lactic acid bacteria (LAB) remain the most common types of microbes used as probiotics, although certain yeasts are also used [9-10].

Fermented drinks like palm wine and corn beer have been noted as potential niches that harbor a rich consortium of microorganisms due to the presence of simple sugars used as a substrate for growth. A study carried out by Chandrasekhar et al. [11] and Parveens and Hafiz, [12] showed that LAB are among the most predominant microorganisms in locally fermented drinks. Palm wine and corn beer are widely consumed beverages in Africa and Cameroon in particular due to their low cost and ready availability. In addition to this extensive consumption, there is very limited cognizance of the inherent health benefits of the microorganisms that are predominant in these beverages [13]. The cholesterol assimilation property among others stands out as one of the most significant functional properties of LAB which can be used to lower cholesterol levels in hypercholesterolemia patients.

However, little is known about the cholesterol lowering efficacy of probiotic LAB from locally harvested palm wine and traditionally processed corn beer in Cameroon. In this study, we isolated and characterized $\mathrm{LAB}$ with probiotic properties and their ability to lower cholesterol in vitro.

\section{Methods}

\section{Sample collection}

Sap from African oil palm (Elaeis guineensis) was procured from palm wine tappers. Sap collection was done following the destructive method described by Onuche et al. [14]. Briefly, the tree was cut down and a cavity created by digging into the soft meristem of the tree trunk. A tube was inserted to make way for sap collection in a sterile plastic bottle. Corn beer was collected with the use of a sterile plastic bottle from corn beer vendors. African oil palm and maize plant were identified at the National Herbarium in Yaounde. The identification was carried out through comparison with the botanic collection of $\mathrm{M}$. Brut $\mathrm{N}^{\circ}$ 379 for African oil palm tree, recorded at the National Herbarium $N^{0} 34163 / \mathrm{HNC}$, while corn beer plant was identified through comparison with the botanic collection of D. Dang $N^{\circ} 81$ also recorded at the National Herbarium under No 18625/SRF/Cam.

All samples were collected in Buea and immediately transported in ice-cool boxes $\left(4^{\circ} \mathrm{C}\right)$ to the University of Buea Life Science Laboratory and allowed for 2 days to undergo fermentation at ambient temperature $\left(21-30^{\circ} \mathrm{C}\right)$ before processing.

Isolation of lactic acid bacteria (LAB) 
Media preparation was performed following the manufacturer's instructions. Tenfold serial dilution was made by transferring $1 \mathrm{ml}$ of each sample into $9 \mathrm{ml}$ of peptone water. The pour plate method was used to enumerate bacteria cells (CFU/ml). Then, $0.1 \mathrm{ml}$ from each dilution was transferred into sterile Petri dishes and covered with molten agar. The plates were incubated at $37^{\circ} \mathrm{C}$ for $24 \mathrm{~h}$. Repeated sub-culture by streaking on MRS agar was carried out to obtain pure colonies. Pure colonies were labeled with codes, with $\mathrm{Pw}$ for palm wine $\mathrm{LAB}$, and $\mathrm{Cb}$ for corn beer $\mathrm{LAB}$ and Arabic numbers attributed starting from 1 . Preliminary identification involving colony morphology, Gram staining, and catalase tests were performed.

\section{Probiotic properties of $L A B$}

The major selection criteria used to determine the probiotic properties of LAB isolates were tolerance to low $\mathrm{pH}$, bile salt tolerance, and in vitro cholesterol assimilation activity. All tests were performed in triplicates and the number of viable colonies in MRS agar plates was counted.

\section{Tolerance to acid $\mathrm{pH}$ values}

Acid tolerance was evaluated following the method described by Guan at al. [15] with slight modifications. Overnight cultures of bacteria cells were washed three times with PBS ( $\mathrm{pH} 7.0)$ to remove impurities and centrifuged (Eppendorf centrifuge 5810 R, New York, USA) for 10 min at $4^{\circ} \mathrm{C}$ at 5,000 rpm. The cell pellets were re-suspended in MRS broth adjusted to pH 2.0 and pH 3.0 (HI991001, Woonsocket, USA) using $3 \mathrm{~N} \mathrm{HCl}$ or $\mathrm{NaOH}$. The cultures were then incubated at $37^{\circ} \mathrm{C}$ for $24 \mathrm{~h}$. Aliquots were taken after $0 \mathrm{~h}$ and $3 \mathrm{~h}$, serially diluted. Samples taken at $0 \mathrm{~h}$ were used as the control. Isolates that exhibited final counts $\geq 10^{3} \mathrm{CFU} / \mathrm{ml}$ or $\geq 10^{6} \mathrm{CFU} / \mathrm{ml}$ at low $\mathrm{pH}$ for $3 \mathrm{~h}$, were considered to have moderate or good resistance, respectively. To perform enumeration, $1 \mathrm{ml}$ of each of the suspensions was serially diluted up to the ten logarithmic fold and the viable microorganisms were counted in triplicates on MRS agar.

\section{Bile tolerance}

The bile salt resistance of selected isolates was determined by the method described by Argyri et al. [16] with minor modifications. Overnight cultures of bacteria cells were washed three times with PBS $(\mathrm{pH} 7.0)$ to remove impurities and centrifuged $\left(5,000 \mathrm{rpm}\right.$ for $10 \mathrm{~min}$ at $\left.4^{\circ} \mathrm{C}\right)$. The cell pellets were re-suspended in MRS broth containing 0.2 and $0.4 \%$ oxgall bile salts (sigma Aldrich, Germany). The cultures were then incubated at $37^{\circ} \mathrm{C}$ for $24 \mathrm{~h}$. Aliquots were taken after $0 \mathrm{~h}$ and $3 \mathrm{~h}$, serially diluted, and plated on MRA agar. Samples taken at $0 \mathrm{~h}$ were used as the control. Resistance to bile salt was evaluated based on viable colony counts on MRS agar in triplicates after incubation at $37^{\circ} \mathrm{C}$ for 0 and $3 \mathrm{~h}$, reflecting the average time spent by food in the small intestine.

\section{Cholesterol assimilation from culture media}

Based on the acid and bile tolerance of the selected strains, the ability of each strain to assimilate cholesterol in vitro was determined by a modified method described by Pereira and Gibson [17]. Bacteria 
strains were inoculated into tubes, each containing $10 \mathrm{ml}$ of MRS broth, $0.4 \%$ bile salts, and $1 \%$ acid solution of cholesterol (Sigma-Aldrich, cat \# C3045-5G, Germany). The cultures were incubated at $37^{\circ} \mathrm{C}$ for $24 \mathrm{~h}$. After incubation, the cultures were centrifuged $\left(5,000 \mathrm{rpm}\right.$ for $10 \mathrm{~min}$ at $\left.4^{\circ} \mathrm{C}\right)$ and the unutilized cholesterol estimated in the supernatant. This was carried out by spectrophotometry (Pharmacia LKB, England) at $540 \mathrm{~nm}$ and compared to the control as described by Ngongang et al. [18]. The percentage of cholesterol assimilation was determined by the equation established by Al-Sahel et al. [19]

$$
A=\left(\frac{B}{C}\right) X 100
$$

Where $A$ is the percentage of cholesterol that remained with the pellet, $B$ is the absorbance of the sample containing the cells, and $\mathrm{C}$ is the absorbance of the sample without cells.

Isolates having in vitro cholesterol assimilation properties were selected for biochemical identification using API 50 CHL assay.

\section{Identification of LAB isolates}

\section{Phenotypic identification of LAB isolates using API $50 \mathrm{CHL}$ kit}

Phenotypic identification of LAB isolates was performed by API 50 CHL (API kit, bioMérieux, France) assay. Purified LAB cultures were cultivated in $20 \mathrm{ml}$ MRS broth incubated at $37^{\circ} \mathrm{C}$ overnight, after which they were washed and re-suspended in $\mathrm{API}{ }^{\circledR} 50 \mathrm{CHL}$ medium (bioMerieux ${ }^{\circledR} \mathrm{SA} 69280$, France). The turbidity of the suspensions was determined by the McFarland method according to the instructions provided by the manufacturer. Cell suspensions were transferred into API $50 \mathrm{CHL}$ strip wells and overlaid with paraffin oil to create an anaerobic condition. The strips were incubated at $37^{\circ} \mathrm{C}$. The results were read after $24 \mathrm{~h}$ and confirmed after $48 \mathrm{~h}$. Fermentation of carbohydrates was indicated by a yellow color except for the esculine test (black). Color reactions were scored against a chart provided by the manufacture [20]. The results were analyzed with API WEB (bioMerieux) database version 5.0.

\section{Genotypic identification of LAB isolates using $16 \mathrm{~S}$ rRNA gene sequencing}

Genomic extraction of the two strains of LAB was determined following the method described by Mulaw et al. [21] with some slight modifications.

\section{DNA extraction of LAB isolates}

The genomic DNA was extracted from pure cultures of isolate Pw4 and Cb5. One ml of each pure liquid culture was centrifuged at 11,500 rpm for $10 \mathrm{~min}$ at $25^{0} \mathrm{C}$ (Eppendorf centrifuge $5810 \mathrm{R}$, New York, USA). The supernatant was decanted and the cell pellets re-suspended into a tube containing $300 \mu$ buffer (10mM Tris- $\mathrm{HCl}, \mathrm{pH} 8.0 ; 50 \mathrm{mM}$ glucose, and $10 \mathrm{mM}$ EDTA) and $3 \mu$ lysozyme $(10 \mathrm{mg} / \mathrm{ml})$. The pellets 
were lysed at $37^{0} \mathrm{C}$ for $60 \mathrm{~min}$ and vortexed every $5 \mathrm{~min}$, followed by placing in ice every $5 \mathrm{~min}$.

Threefold (300) $\mu$ l of lysis buffer and $3 \mu$ RNAse were added to the mixture and incubated for 30 min and cooled on ice for $1 \mathrm{~min}$. Then, $100 \mu$ of $7.5 \mathrm{M}$ solution of sodium acetate was added and vortexed for 25 seconds and centrifuged (Eppendorf centrifuge 5810 R, New York, USA) at 13,000 rpm for 10 min at $4^{\circ} \mathrm{C}$. The supernatant was transferred into a sterile tube, and $300 \mu$ isopropanol was added and mixed gently. The resulting mixture was centrifuged at $13,000 \mathrm{rpm}$ for $10 \mathrm{~min}$ at $4^{\circ} \mathrm{C}$ (Eppendorf centrifuge $5810 \mathrm{R}, \mathrm{New}$ York, USA). Isopropanol was carefully removed by the use of a sterile Eppendorf pipette without dislocating the DNA pellets. The tubes were air-dried by inverting them on sterile filter paper. The DNA was washed by adding $400 \mu$ of $70 \%$ ethanol and centrifuged at 5,000 rpm for 2 min at ambient temperature. The sediments were dried at $37^{\circ} \mathrm{C}$ for $10 \mathrm{~min}$ and finally dissolved in $30 \mu \mathrm{l} \mathrm{TE}$ buffer and stored at $-20^{\circ} \mathrm{C}$ for further study.

\section{Amplification of DNA in polymerase chain reaction (PCR)}

The 16S rRNA coding region sequence was selected and amplified by PCR using the universal primersforward (5'- AGAGTTTGATCCTGGCTCAG -3) - reverse (5'- ACGGCTACCTTGTTAACGACTT -3). The PCR conditions for the 30 cycles were as follows: $95^{\circ} \mathrm{C} 5 \mathrm{~min}$ (initial denaturation), $94^{\circ} \mathrm{C}$ for $\min 30 \mathrm{~s}$ (denaturation), $42^{\circ} \mathrm{C}$ for $1 \mathrm{~min} 30 \mathrm{~s}$ (annealing), $72^{\circ} \mathrm{C}$ for $1 \mathrm{~min} 30 \mathrm{~s}$ (extension) $72^{\circ} \mathrm{C}$ for 10 min (and final extension). The PCR amplicons were examined by gel electrophoresis ( $1 \% \mathrm{w} / \mathrm{v})$.

\section{Gel electrophoresis}

Two $\mu$ of each amplification mixture was subjected to electrophoresis in $1.5 \%(\mathrm{w} / \mathrm{v})$ agarose gels in $0.5 \mathrm{x}$ TAE buffer for $1 \mathrm{~h}$ at100 V. The DNA molecular mass marker (250 to $10000 \mathrm{bp}$ ) from inqaba biotech, South Africa was used as the standard. After electrophoresis, the gels were stained with ethidium bromide, washed, and photographed with UV transilluminator (Bio-Rad, Hercules, CA, USA). The partial 16S rRNA sequence analysis of the PCR products was sequenced by inqaba biotech, South Africa. The sequences obtained were compared using BLAST (basic local alignment search tool) and submitted to the GenBank sequence database for accession numbers [22]. A phylogenetic tree was constructed using MEGA 10 software to reduce all positions containing gaps and missing data in the trail sequence in order to evaluate the evolutionary relationship of Pw4 and $\mathrm{Cb} 5$ and their close relations.

\section{Statistical analysis}

All the tests were performed in triplicate, and the results were expressed as mean \pm standard deviation. Data were analyzed by the one-way ANOVA plus post hoc Duncan's test by Statistical Package for Social Scientist (SPSS) version 20.0. Statistical significance was determined at $p<0.05$. The phylogenetic trees were constructed using MEGA10 (version 10.0).

\section{Results}


A total of 60 LAB cultures were isolated on MRS agar. Forty-two of these cultures were isolated from palm wine and 18 from corn beer all sourced from Buea, South West Region of Cameroon. Preliminary identification of colonies carried out on the basis of cell morphology, microscopic examination and biochemical tests revealed smooth, oval, and cream white colonies on MRS agar plate. However, only ten colonies were catalase negative and Gram positive under microscopic examination and were considered as presumptive LAB. Table 1 shows the preliminary identification of the isolates.

Table 1.

Phenotypic characteristics of lactic acid bacteria

\begin{tabular}{ccccc}
\hline Isolates & Catalase test & Gram reaction & Shape & Origin of isolate \\
\hline Pw1 & - & + & Rods & Palm wine \\
Pw2 & - & + & Shorts rods forming & Palm wine \\
& & & clusters & \\
Pw3 & - & + & Shorts rods & Palm wine \\
Pw4 & - & + & Rods & Palm wine \\
Cb1 & - & + & Rods & Corn beer \\
Cb2 & - & + & Chain forming cocci & Corn beer \\
$\mathrm{Cb3}$ & - & + & Short rods & Corn beer \\
$\mathrm{Cb} 4$ & - & + & Cocci & Corn beer \\
$\mathrm{Cb5}$ & - & + & Shorts rods & Corn beer \\
$\mathrm{Cb} 6$ & - & + & Chain forming cocci & Corn beer \\
\hline
\end{tabular}

(+) Positive (-) Negative reactions

\section{Probiotic properties of LAB isolates}

\section{Resistance to acid}

The viable counts of all isolates ranged from 3.9-7 log $\mathrm{CFU} / \mathrm{ml}$ after $3 \mathrm{~h}$ of exposure at $\mathrm{pH}$ 2.0. This ability of the strains to survive the acidic $\mathrm{pH}$ value after $3 \mathrm{~h}$ of incubation at $37^{\circ} \mathrm{C}$ is presented in figures $1 \mathrm{a}$ and 1b. Isolates Pw1, Pw4, Cb1, Cb3, Cb4, Cb5 and Cb6 had viable counts greater than 6 log CFU/ml, which was significantly different $(\mathrm{p}<0.05)$ from the control $(\mathrm{pH} 2.0$ at $3 \mathrm{~h})$. On the contrary, isolates Pw2, Pw3 and $\mathrm{Cb} 2$ had viability below $5 \mathrm{log} \mathrm{CFU} / \mathrm{ml}$ which was not significantly different ( $p>0.05$ ) when compared to the control. However, when the $\mathrm{pH}$ value was increased to 3.0 for $3 \mathrm{~h}$, the viability of all isolates 
increased in the range of 4.3-7 log CFU/ml. The viable counts of isolates Pw1, Pw3, Pw4, Cb1, Cb3, Cb4, $\mathrm{Cb} 5, \mathrm{Cb} 6$ exceeded $6 \log \mathrm{CFU} / \mathrm{ml}(\mathrm{p}<0.05$ at pH3.0 for $3 \mathrm{~h})$. Contrariwise, the viability of isolates Pw2 and $\mathrm{Cb} 2$ fell below $5 \log \mathrm{CFU} / \mathrm{ml}(\mathrm{p}>0.05)$. In total, isolate Pw1, Pw4, Cb1, Cb3, Cb4, Cb5 and Cb6 maintained a high viable count despite the change in $\mathrm{pH}$ values.

\section{Resistance to bile salt}

The viability of all the isolates ranged from 3.9-7.5 log CFU/ml after $3 \mathrm{~h}$ of exposure to $0.2 \%$ bile salt concentration. The viable count of isolate Pw1, Pw4, Cb1, Cb2, Cb4, Cb5 and $\mathrm{Cb} 6$ was higher than $6 \log$ $\mathrm{CFU} / \mathrm{ml}$ which was significantly different from the control $(\mathrm{p}<0.05)$. On the other hand, isolates Pw2, Pw3 and $\mathrm{Cb} 3$ had viability below $4.5 \mathrm{log} \mathrm{CFU} / \mathrm{ml}$. When the bile salt concentration was increased to $0.4 \%$ after $3 \mathrm{~h}$, the viability of all the isolates fell in the range of 3.1-7 log CFU/ml. The viability of Pw2, Pw4, Cb1, $\mathrm{Cb} 4, \mathrm{Cb} 5$ and $\mathrm{Cb} 6$ were greater than $6 \mathrm{log} \mathrm{CFU} / \mathrm{ml}$ which were not significantly greater than the control ( $p>0.5)$. On the contrary, isolates Pw1, Pw3, Cb2 and Cb3 had viable counts below 5 log CFU/ml which were significantly different from the control $(p<0.5)$.

In total, isolates $\mathrm{Pw} 4, \mathrm{Cb} 1, \mathrm{Cb} 4, \mathrm{Cb} 5$ and $\mathrm{Cb} 6$ maintained good viability irrespective of the change in bile salt concentration. This ability of the strains to survive the bile salt concentrations after $3 \mathrm{~h}$ of incubation at $37^{\circ} \mathrm{C}$ is presented in figures $2 \mathrm{a}$ and $2 \mathrm{~b}$.

\section{Cholesterol assimilation from culture media}

The amount of cholesterol assimilated in-vitro ranged from $28-89 \%$ after $24 \mathrm{~h}$ of incubation in the presence of bile salt (figure 3). Seven strains assimilated cholesterol at a variable extent with Pw1, Pw4, $\mathrm{Cb} 4$ and $\mathrm{Cb} 5$ which displayed excellent assimilation property (>75\%). Contrariwise, Pw3 and Cb3 had poor cholesterol $(<45 \%)$ uptake and did not grow well in the medium. Strains Pw4 and Cb5 were selected for further studies.

\section{Identification of LAB isolates}

\section{Phenotypic identification of LAB isolates using API $50 \mathrm{CHL}$ kit assay}

Results from API $50 \mathrm{CH}$ test kits and API web identified the two LAB isolates (Pw4) from palm wine Lactobacillus plantarum with similarity $99.6 \%$ and (Cb5) from corn beer Lactobacillus. pentosus $99.5 \%$ (Table 2). There was an insignificant variation in the utilization of carbohydrates sources of the API CHL 50 kit by Pw4 and Cb5 isolates (Table 3). 
Table 2:

Phenotypic Identification of lactic acid bacteria

\begin{tabular}{llll}
\hline Lab code & Source & Identification & Similarity index \% \\
\hline Pw4 & Palm wine & L. plantarum & $99.6 \%$ \\
Cb5 & Corn beer & L. pentosus & $99.5 \%$ \\
& & \\
\hline
\end{tabular}

Table 3:

Carbohydrates fermentation by lactic acid bacteria isolates using API $50 \mathrm{CHL}$ kit $^{\mathrm{a}}$.

\begin{tabular}{|c|c|c|c|c|c|c|c|c|c|c|c|c|c|c|c|c|c|c|c|c|c|c|c|c|c|c|c|c|}
\hline $\begin{array}{r}\text { Test } \\
\text { number }\end{array}$ & 0 & 1 & 2 & 3 & 4 & 5 & 6 & 7 & 8 & 9 & 10 & 11 & 12 & 13 & 14 & 15 & 16 & 17 & 18 & 19 & 20 & 21 & 22 & 23 & 24 & 25 & 26 & 27 \\
\hline Strain code & 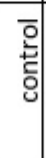 & 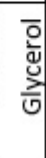 & 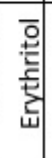 & $\frac{1}{\partial}$ & -1 & 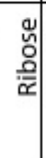 & $\begin{array}{l}\stackrel{y}{\nu} \\
\frac{\hat{0}}{\grave{X}} \\
\frac{1}{0}\end{array}$ & 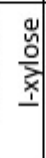 & $\begin{array}{l}\overline{0} \\
\text { 훈 } \\
\text { 휨 }\end{array}$ & 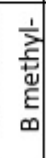 & 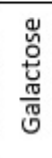 & $\begin{array}{l}\stackrel{\check{U}}{0} \\
\frac{\mathrm{O}}{0}\end{array}$ & 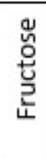 & $\begin{array}{l}\stackrel{y}{0} \\
\stackrel{5}{E} \\
\sum_{\Sigma}^{\pi}\end{array}$ & 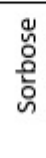 & 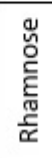 & $\begin{array}{l}\overline{0} \\
\text { t: } \\
\text { 믐 }\end{array}$ & $\begin{array}{l}\overline{0} \\
\stackrel{\underline{N}}{\mathrm{O}} \\
\text { 으 }\end{array}$ & 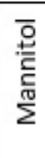 & 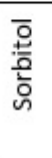 & 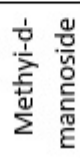 & 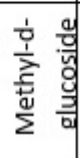 & 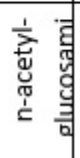 & 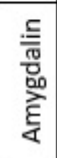 & 采 & 壱 & $\frac{\sqrt[]{\mathrm{U}}}{\frac{\mathrm{C}}{\mathrm{N}}}$ & $\begin{array}{l}\text { 잉 } \\
\text { 응 } \\
\overline{0}\end{array}$ \\
\hline Pw4 & - & - & - & - & + & + & - & - & - & - & + & + & + & + & - & - & - & - & + & + & + & + & + & + & + & + & + & + \\
\hline Cb5 & - & - & - & - & + & + & + & ' & + & + & + & + & + & + & + & - & - & - & + & + & + & + & + & + & + & + & + & + \\
\hline
\end{tabular}

\begin{tabular}{|c|c|c|c|c|c|c|c|c|c|c|c|c|c|c|c|c|c|c|c|c|c|c|c|}
\hline Test sample & 28 & 29 & 30 & 31 & 32 & 33 & 34 & 35 & 36 & 37 & 38 & 39 & 40 & 41 & 42 & 43 & 44 & 45 & 46 & 47 & 48 & 49 & Identified species \\
\hline Strain code & 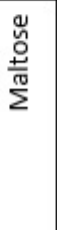 & 岕 & 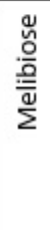 & 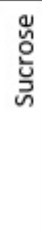 & 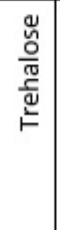 & 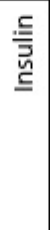 & 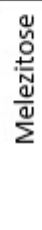 & 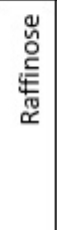 & 㤐 & 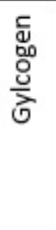 & 总 & 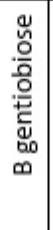 & 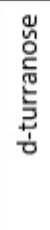 & 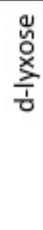 & 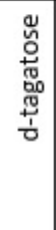 & 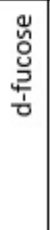 & 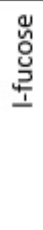 & 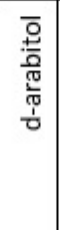 & 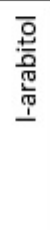 & 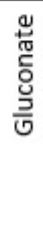 & 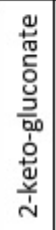 & 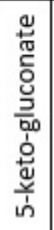 & \\
\hline Pw4 & + & + & + & + & + & - & + & - & ? & ? & - & + & + & - & + & - & - & - & - & ? & - & - & $\begin{array}{r}\text { Lactobacillus } \\
\text { plantarum }\end{array}$ \\
\hline Cb5 & + & - & + & + & + & ' & + & - & - & - & - & + & + & + & + & - & - & - & - & ? & - & - & $\begin{array}{r}\text { Lactobacillus } \\
\text { pentosus }\end{array}$ \\
\hline
\end{tabular}

\section{Genotypic identification of LAB isolates}

The genotype identification of DNA using universal primer showed clear bands of isolates on agarose gel with approximate molecular weight 15000 bp. Results obtained using BLAST identification and MEGA 10 software revealed close similarity of $97.4 \%$ of Pw4 to Lactobacillus brevis strain ATC (Accession no. NR116238) and 99.54\% of Cb5 to Enteroccocus faecium strain NBRC (Accession no.NR113904). 
Phylogenetic trees of these selected isolates based on 16S RNA gene sequences are presented in Figures $4 a$ and $4 b$.

Table 4:

Genotypic Identification of LAB Isolates.

\begin{tabular}{ccccc}
\hline Lab code & Source & Identification & Similarity index \% & Accession no. \\
\hline Pw4 & Palm wine & Lactobacillus. brevis ATCC & $97.4 \%$ & NR116238 \\
Cb6 & Corn beer & Enterococcus faecium NBRC & $99.54 \%$ & NR113904 \\
& & & & \\
\hline
\end{tabular}

\section{Discussion}

Locally harvested palm wine and traditionally processed corn beer have been exploited as suitable sources for screening various LAB [23]. In Cameroon, palm wine and corn beer are widely consumed with little or no knowledge of the presence of a predominant LAB population [13]. Out of the fifty samples collected and grown on MRS agar plates, only ten isolates had morphological (microscopic and macroscopic), biochemical features similar to LAB (Table 1) as reported by Bennani et al. [24]. Four of these isolates were sampled from palm wine coded as Pw1, Pw2, Pw3, and Pw4 and six from corn beer coded $\mathrm{Cb} 1, \mathrm{Cb} 2, \mathrm{Cb} 3, \mathrm{Cb} 4, \mathrm{Cb} 5$ and $\mathrm{Cb} 6$. This implies that LAB cultures were predominant in corn beer when compared to palm wine. Fresh palm wine has been reported to have a rich population of microbial load than corn beer [25]. This causes rapid bioconversion of sugar present in palm wine to alcohol during fermentation. However, in this study, LAB cultures were isolated more (60\%) from corn beer than from palm wine (40\%) (Table1). This indicated that a high microbial population is not synonymous to a high LAB presence. The finding in this study concurs with that of Nwachukwu et al. [26] who successfully isolated LAB from fermented samples.

Probiotic LAB have been shown to have inherent health benefits and approved for human consumption primarily because they have acquired a status of GRAS (Generally Regarded as Safe) and QPS (Qualified Presumption of Safety) by the American Food and Drug Agency (FDA) and the European Food Safety Authority (EFSA), respectively [27]. One of such functional property proven to be more effective in hypercholesterolemia patients involves cholesterol assimilation in the liver and ileum. Recent studies have proven that probiotic LAB are able to assimilate cholesterol to a significant margin [28-29]. Gilliland et al. [30] were the first to show that in vitro efficiency of lactobacilli could be directly associated with their ability to assimilate cholesterol. As a result, in-vitro removal of cholesterol by lactobacilli has been 
consistently used as a screening tool for the selection of probiotic strain. In this study, in vitro cholesterol assimilation assay was performed to assess the cholesterol assimilation property of ten LAB. For efficient cholesterol assimilation, $0.4 \%$ bile salt was added to the medium and grown under aerobiosis as described by Anandharaj et al. [31]. The results obtained (figure 3) showed two isolates (Pw4 and Cb5) with the best cholesterol assimilation ability ( $>80 \%)$. This implies that isolate Pw4 and $\mathrm{Cb} 5$ can efficiently be used to assimilate cholesterol in vitro. A similar study by Anila et al. [32] and Malakar et al. [33] revealed that L. brevis PLA 7, L. brevis PLA 14 and Enteroccocus faecium BASTUS 4 and 5 respectively isolated from fermented beverages were able to assimilate cholesterol significantly in vitro. A possible mechanism of cholesterol assimilation of Pw4 and $\mathrm{Cb} 5$ was the cell wall binding and incorporation of cholesterol within their phospholipid layer as described by Ooi and Lion [34]. However, Ramasamy, [35], highlighted that bile salt hydrolytic activity (BSH) of probiotics stands as one of the most significant mechanisms for cholesterol removal and has been proposed by many researchers as a prerequisite for probiotic selection. Evaluating the in vitro cholesterol assimilation was significant to extrapolate a similar trend during in vivo studies. A study carried out by Ngongang et al. [18] revealed alike trend during cholesterol assimilation in MRS culture medium as well as in albino rats.

In spite of the high cholesterol assimilation ability of $L A B$, they must overcome the stressful conditions of acid (stomach $\mathrm{pH}$ ) and bile (duodenum) before initiating their health benefit (cholesterol lowering effect) in the ileum. Acid and bile tolerance is therefore regarded as a prerequisite for any LAB to be considered as a probiotic [36]. The survival of $L A B$ in the stomach is important because the $\mathrm{pH}$ of the stomach $(\mathrm{HCl}$ acid) can be as low as 1.5 (without food), inhibiting metabolic activities thereby retarding the viability of Lactobacillus sp. The transition of this acidic medium ( $3 \mathrm{~h})$ is vital for probiotics to initiate their beneficial effects on the distal part of the gut [37]. In this study, ten presumptive LAB were exposed to $\mathrm{pH} 2$ and 3 for $3 \mathrm{~h}$ to assess their ability to withstand stressful conditions.

Among the ten isolates, seven had viable counts reaching $6 \log \mathrm{CFU} / \mathrm{ml}$ irrespective of the $\mathrm{pH}$ change. This implied that these isolates were able to tolerate acidic conditions at pH 2.0 and pH 3.0 and were therefore considered acid tolerant. Similar findings have been reported by Somashekaraiah et al. [38], who reported excellent acid tolerant properties of Enterococcus faecium (MH748610-MYSN) and Lactobacillus brevis (MH748630-MYSN) isolated from neera ( a naturally fermenting coconut palm nectar). The increase in viability in $\mathrm{pH} 3.0$ compared to $\mathrm{pH} 2.0$ was similar to the results obtained by Vanniyasingam et al. [39].

Evaluating tolerance to bile is important because probiotic bacteria have to transit the duodenum (where bile acid is present) before initiating cholesterol assimilation in the ilium [40]. Bile salt is synthesized in the liver from cholesterol and stored in the gall bladder from where it is secreted into the duodenum in a conjugated form during fat metabolism. The physiological concentrations of human bile salts range from 0.3 to $0.5 \%$ [41]. In this study, the viable count of the isolates was determined after exposure to 0.2 and $0.4 \%$ bile salt after $3 \mathrm{~h}$ of incubation. Seven strains were found to tolerate $0.2 \%$ bile salt, while six strains were able to tolerate $0.4 \%$ bile salt. This implies that high bile concentration affects the viability of isolates. This is because disruption of cellular homeostasis causes the dissociation of the lipid bilayer

Page $11 / 20$ 
and integral protein of their cell membranes, resulting in bacterial content leakage and cell death [42]. A similar result showed that Enterococcus faecium (MH748610-MYSN 18) and Lactobacillus brevis (MH748630-MYSN) isolated from some fermenting coconut palm nectar had bile salt tolerance of more than $80 \%$ [38]. Bile salt hydrolytic activity which is associated with the capacity to eliminate cholesterol from the intestinal environment has been shown to be an important mechanism for bile tolerance [43].

Conventional phenotypic methods alone are insufficient for the identification of LAB. Reliability can be achieved by the use of molecular techniques. The 16S rRNA gene is found to be a powerful tool for appreciating genetic variability among different species [44], which allows for the design and use of universal primers to discover and classify organisms into a wide range of taxa. Mulaw et al. [45] and Dowarah et al. [46] have revealed the strain level identification of diverse LAB with potent probiotic properties isolated from traditionally fermented foods and other substrates using phylogenetic estimation of $16 \mathrm{~S}$ rDNA genes. In this study, the results obtained from the two identification methods did not agree (Tables 2 and 4). However, discrepancies between sequencing and phenotypic (API 50CH kit) methods have been reported for LAB and other bacteria [47]. The API 50 CHLassay is intended uniquely for the identification of those species included in the database. As a result, the strains not found in the identification table provided by bioMérieux SA, were successfully identified using the 16S rRNA gene sequencing. Moreover, a study by Bağder et al. [48] compared the results of the API $50 \mathrm{CHL}$ test with $16 \mathrm{~S}$ rRNA results and found that the API test did not give reliable identification results, with only 71 out of 152 tested isolates in agreement.

In this study, a phylogenetic tree for each gene was constructed by the Maximum Likelihood method and minimum evolution method to access the evolutionary relationship between local samples (Pw4 and $\mathrm{Cb5}$ ) and the highest query cover above $90 \%$ of samples [49]. The sequences of Pw4 and Cb5 showed similarity of $97.4 \%$ at $97 \%$ query coverage to Lactobacillus brevis strain ATCC 14869 (Accession no. NR116238) and $99.54 \%$ at $97 \%$ query coverage to Enteroccocus faecium strain NBRC 100486 (Accession no.NR113904) respectively. Taken into consideration these two identification methods in this study, the results obtained affirms the need of using molecular methods for typing newly isolated microorganisms.

\section{Conclusion}

Lactobacillus brevis strain ATCC 14869 (Accession no. NR116238) and Enteroccocus faecium strain NBRC 100486 (Accession no.NR113904) isolated from palm wine and corn beer in Buea, have good acid and bile tolerance and can be used in cholesterol assimilation especially for patients displaying symptoms of high serum cholesterol. The properties of these LABs identified, can permit them overcome the stressful acid and bile salt conditions in the stomach and duodenum respectively, to provide health benefits in the gut.

\section{Abbreviations}

16SrRNA: 16S ribosomal ribonucleic acid 
API: Analytical Profile Index

CVD: Cardiovascular disease

CFU/ml: Colony forming unit per millilitre

LAB: Lactic acid bacteria

MRS: Man Rogosa and Sharpe agar

PCR: Polymerase Chain Reaction

WHO: World Health Organization

\section{Declarations}

\section{Acknowledgements}

We acknowledge the support and technical assistance of the Biotechnology Unit in the University of Buea.

\section{Funding}

Not applicable. (No specific funding or grant)

\section{Consent for publication}

Not applicable

\section{Availability of data and materials}

The datasets used and/or analyzed during the current study available from the corresponding author on reasonable request.

\section{Competing Interest}

We declare no competing interests

\section{References}

1. Yang J, Wang L, Jia R. Role of de novo cholesterol synthesis enzymes in cancer. J Cancer. 2020: 11(7):1761-1767. doi:10.7150/jca.38598

2. Zhong VW, Van Horn L, Cornelis MC, Wilkins JT, Ning H, Carnethon MR, Greenland P, et al. Associations of Dietary Cholesterol or Egg Consumption with Incident Cardiovascular Disease and Mortality. JAMA. 2019; 321(11):1081-1095. doi: 10.1001/jama.2019.1572. 
3. Ahire JJ, Bhat AA, Thakare JM, Pawar PB, Zope DG, Jain RM, Chaudhari BL. Cholesterol assimilation and biotransformation by Lactobacillus helveticus. Biotechnol Lett 2012:34:103-107

4. Wealth Health Organization (WHO). Cardiovascular Disease; Fact sheet №317, Geneva, Switzerland, September, 2009. Available on: http://www.who.int/mediacentre/factsheets/fs317/en/print.html (accessed on 20 August 2020).

5. Nkoke C, Jingi AM, Makoge C, Teuwafeu D, Nkouonlack C, Dzudie A Epidemiology of cardiovascular diseases related admissions in a referral hospital in the South West Region of Cameroon: A crosssectional study in sub-Saharan Africa. PLoS ONE. 2019:14(12): e0226644. https://doi. org/10.1371/journal.pone.0226644

6. Harcombe Z, Baker JS, DiNicolantonio JJ, Grace F, Davies B. Evidence from randomized controlled trials does not support current dietary fat guidelines: a systematic review and meta-analysis. Open Heart. 2016: 3(2):e000409. DOI: 1136/openhrt-2016-000409

7. Janapala US, Reddivari AKR. Low Cholesterol Diet. [Updated 2020 Jul 10]. In: StatPearls [Internet]. Treasure Island (FL): StatPearls Publishing; 2020 Jan-. Available from:

https://www.ncbi.nlm.nih.gov/books/NBK551722/

8. Hill C, Guarner F, Reid G, Gibson GR, Merenstein DJ, Pot B, Morelli L et al. The International Scientific Association for Probiotics and Prebiotics consensus statement on the scope and appropriate use of the term probiotics. Rev. Gastroenterol. Hepatol.2014: 11, 506-514. doi: 10.1038/nrgastro.2014.66

9. Lv LX, Hu XJ, Qian GR, Zhang H, Lu HF, Zheng BW, Jiang L et al. Administration of Lactobacillus salivarius LI01 or Pediococcus pentosaceus LI05 improves acute liver injury induced by Dgalactosamine in rats. Appl Microbiol Biotechnol. 2014; 98(12):5619-32. doi: 10.1007/s00253-0145638-2.

10. Mingmongkolchai S, and Panbangred W.Bacillus probiotics: An alternative to antibiotics for livestock production.2018: Journal of Applied Microbiology, 124(6):1334-1346. https://doi.org/10.1111/jam.13690

11. Chandrasekhar K, Sreevani S, Seshapani P, Pramodhakumari J. A Review on palm wine. Int. J. Res. Biol. Sci. 2012:2:33-38.

12. Parveens S, Hafiz F. Fermented cereal from indigenousraw materials. Pak. J.Nutr. 2003:2(5):289-291.

13. Ezeronye OU and Legras JL. Genetic Analysis of Saccharomyces Cerevisiae Strains Isolated From Palm Wine In Eastern Nigeria. Comparison with other African Strains. J. Appl. Microbiol. 2009:106(5):1569-1578.

14. Onuche P, Shomkegh SA, Tee TN. Palm wine tapping methods among Idoma and Tiv ethnic groups of Benue state, Nigeria: Implications on conservation of palm trees (Elaeis guineensis). Journal of Environmental Issues and Agriculture in Developing Countries. 2012: 4: 86-91.

15. Guan X, Xu Q, Zheng Y, Qian L, Lin B. Screening and characterization of lactic acid bacteria strains that produce fermented milk and reduce cholesterol levels. Brazillian Journal of Microbiology. 2017:48, 730-739 
16. Argyri AA, Zoumpopoulou G, Karatzas KA, Tsakalidou E, Nychas GJ, Panagou EZ, Tassou CC. Selection of potential probiotic lactic acid bacteria from fermented olives by in vitro tests. Food Microbiol. 2013; 33(2):282-91. doi: 10.1016/j.fm.2012.10.005.

17. Pereira DI, Gibson GR. Cholesterol assimilation by lactic acid bacteria and Bifidobacteria isolated from the human gut. Applied and Environmental Microbiology, 2002: 68(9): 4689-4693.

Doi:10.1128/AEM.68.9.4689-4693.2002

18. Ngongang TFE, Tiencheu B, Fossi BT, Achidi AU, Shiynyuy DM, Womeni HM, François ZN. Isolation and Identification of Cholesterol Lowering Probiotic Bacteria from Palm Wine (Raffia mambillensis). Journal of Microbiology Research. 2016:6(5):93-102.

https://doi.org/10.5923/j.microbiology.20160605.01

19. Al-Sahel AA, Metwali AAM, Abu-Tarboush HM. Bile salts and acid tolerance and cholesterol removal from media by some lactic acid bacteria and bifidobacteria. Journal of Saudi Society for Food and Nutrition. 2006: 1(1): 1-17 https://doi.org/10.1016/j.fm.2012.10.005

20. De Angelis M, Corsetti A, Tosti N, Rossi J, Corbo MR, Gobbetti M. Characterization of non-starter lactic acid bacteria from Italian ewe cheeses based on phenotypic, genotypic, and cell wall protein analyses. Appl Environ Microbiol. 2001; 67(5):2011-20. doi: 10.1128/AEM.67.5.2011-2020.2001. PMID: 11319075; PMCID: PMC92830.

21. Mulaw G, Sisay Tessema T, Muleta D, Tesfaye A. In Vitro Evaluation of Probiotic Properties of Lactic Acid Bacteria Isolated from Some Traditionally Fermented Ethiopian Food Products. Int J Microbiol. 2019 Aug 25; 2019:7179514. doi: 10.1155/2019/7179514. Erratum in: Int J Microbiol. 2020;24;2020:6401356.

22. Boubezari MT, Idoui T, Hammami R, Fernandez B, Gomaa A, and Fliss I. Bacteriocinogenic properties of Escherichia coli P2C isolated from pig gastrointestinal tract: purification and characterization of microcin V. Microbiol.2018: 200, 771-782. doi: 10.1007/s00203-018-1482-6

23. Fossi BT, Irene A, Frederick T, Kome EL, Theresa AN. Lactic acid bacteria from traditionally processed corn beer and palm wine against selected food-borne pathogens isolated in south west region of Cameroon. African Journal of Microbiology Research.2016: 10(30), 1140-1147. https://doi.org/10.5897/ajmr2016.8143

24. Bennani S, Mchiouer K, Rokni Y, Meziane M. Characterisation and Identification of lactic acid bacteria isolated from Moroccan raw cow's milk. Journal of Materials and Environmental Sciences. 2017. 8(S), pp. 4934-4944

25. Satyalakshmi S, Bhavya Sindhu K, Usha Rani G, Hima Bindu M, Trishali K. Study of Microbial and Anti-microbialProperties of Palm Wine Der Pharmacia Lettre, 2018;10(10):1-9 Available online at scholarsresearchlibrary.com

26. Nwachukwu E, Achi OK, ljeoma IO. Lactic acid bacteria in fermentation of cereals for the production of indigenous Nigerian foods. Afr. J. Food Sci.Technol. 2010; 1(2):21-26

27. EFSA Panel on Biological Hazards (BIOHAZ), Koutsoumanis K, Allende A, Alvarez-Ordóñez A, Bolton D, Bover-Cid S, Chemaly M, Davies R, De Cesare A, et al. Scientific Opinion on the update of the list of 
QPS-recommended biological agents intentionally added to food or feed as notified to EFSA (20172019). EFSA J. 2020 Feb 3; 18(2):e05966. doi: 10.2903/j.efsa.2020.5966. PMID: 32874212; PMCID: PMC7448045.

28. Wang L, Guo M-J, Gao Q, Yang J-F, Yang L, Pang X-L, \& Jiang X-J. The effects of probiotics on total cholesterol. A meta-analysis of randomized controlled trials. Medicine 2018; 97(5), e9679. https://doi.org/10.1097/MD.0000000000009679

29. Mo R, Zhang X, Yang Y. Effect of probiotics on lipid profiles in hypercholesterolaemic adults: A metaanalysis of randomized controlled trials. Medicina Clinica. 2019; 152(12): 473-481. https://doi.org/10.1016/j.medcli.2018.09.007

30. Gilliland S E, Staley T E, Bush L J. Importance of bile tolerance of Lactobacillus acidophilus used as dietary adjunct. 1984; Dairy Sci. 67:3045- 3051

31. Anandharaj M, Sivasankari B, Rani RP. Effects of probiotics, prebiotics and synbiotics on hypercholesterolemia: A review. Chin. J. Biol. 2014. https://doi.org/10.1155/2014/572754

32. Anila K, Kunzes A, Bhalla TC. In Vitro Cholesterol Assimilation and Functional Enzymatic Activities of Putative Probiotic Lactobacillus sp. İsolated from Fermented Foods/Beverages of North West India. J. Nutr. Food Sci. 2016; 6: 467. doi:10.4172/2155-9600.1000467

33. Malakar B, Das AJ, Deka SC. In vitro probiotic potential of enterococcus species isolated from tungrymbai, a fermented soybean product of meghalaya, India. 2017: 46 (3) 297-304 DOI: 10.1556/066.2016.0017.

34. Ooi LG, Liong MT. Cholesterol-lowering effects of probiotics and prebiotics: a review of in vivo and in vitro findings. Int J Mol Sci. 2010; 17; 11(6):2499-522. doi: 10.3390/ijms11062499.

35. Ramasamy K, Shafawi ZM, Mani V, Wan HY, Abdul Majee, AB. Hypocholesterolaemic Effects of Probiotics, Complementary Therapies for the Contemporary Healthcare, Marcelo Saad and Roberta de Medeiros.2012; IntechOpen, DOI: 10.5772/50785. Available from: https://www.intechopen.com/books/complementary-therapies-for-the-contemporaryhealthcare/hypocholesterolaemic-effects-of-probiotics

36. Palachum W, Chisti Y, Choorit W. In-vitro assessment of probiotic potential of Lactobacillus plantarum WU-P19 isolated from a traditional fermented herb. Ann Microbiol. 2018; 68, 79-91 https://doi.org/10.1007/s13213-017-1318-7

37. Kavitha Isolation, Characterization, Determination of Probiotic Properties of Lactic Acid Bacteria from Human Milk. Journal of Pharmacy and Biological Sciences. 2013; 7(3):01-07

38. Somashekaraiah R, Shruthi B, Deepthi BV. Sreenivasa MY. Probiotic Properties of Lactic Acid Bacteria Isolated From Neera: Naturally Fermenting Coconut Palm Nectar. Front. Microbiol. 2019; 10:1382. doi: 10.3389/fmicb.2019.01382.

39. Vanniyasingam J, Kapilan R, Vasantharuba S. Isolation and characterization of potential probiotic lactic acid bacteria isolated from cow milk and milk products. AGRIEAST: Journal of Agricultural Sciences. 2019; 13(1):32-43. DOI: http://doi.org/10.4038/agrieast.v13i1.62 
40. Adetoye A, Pinloche E, Adeniyi, BA, Ayeni FA. Characterization and anti-salmonella activities of lactic acid bacteria isolated from cattle faeces. BMC Microbiol 18, 96 (2018). https://doi.org/10.1186/s12866-018-1248-y

41. Mainville I, Arcand Y, Farnworth ER. A dynamic model that simulates the human upper gastrointestinal tract for the study of probiotics. Int J Food Microbiol. 2005;99 (3):287-96. Epub 2005/04/06pmid:15808363.

42. Mandal S, Puniya AK, Singh K. Effect of alginat concentration on survival of encapsulated Lactobacillus casei NCDC-298. International Dairy Journal. 2006: 16: 1190- 1195

43. Baick SC, Kim CH. Assessment of characteristics and functional properties of Lactobacillus species isolated from kimchi for dairy use. Korean J. Food Sci. An. 2015: 35(3): 339-349.

44. La Scola B, Zeaiter Z, Khamis A, Raoult D. Gene-sequence-based criteria for species definition in bacteriology: the Bartonella paradigm. Trends Microbiol. 2003;11(7):318-21. doi: 10.1016/s0966842x(03)00143-4. PMID: 12875815.

45. Mulaw G, Sisay Tessema T, Muleta D, Tesfaye A. In Vitro Evaluation of Probiotic Properties of Lactic Acid Bacteria Isolated from Some Traditionally Fermented Ethiopian Food Products. Int J Microbiol. 2019;2019:7179514. doi: 10.1155/2019/7179514. Erratum in: Int J Microbiol. 2020; 24;2020:6401356. PMID: 31534458; PMCID: PMC6732631.

46. Dowarah R, Verma AK, Agarwal N, Singh P, Singh BR. Selection and characterization of probiotic lactic acid bacteria and its impact on growth, nutrient digestibility, health and antioxidant status in weaned piglets. PLOS ONE. 2018:13(3): e0192978. https://doi.org/10.1371/journal.pone.0192978

47. Gomes BC, Esteves ICV, Palazzo AL, Darini GE, Felis LA, Sechi BDG. M. Prevalence and characterization of Enterococcus spp. Isolated from Brazilian foods. Food Microbiology. 2008; 25 : 668-675

48. Bağder Elmacı S, Tokatlı M, Dursun D, Özçelik F, Şanlıbaba P. Phenotypic and genotypic identifıcation of lactic acid bacteria isolated from traditional pickles of the Çubuk region in Turkey. Folia Microbiol (Praha). 2015; 60(3):241-51. doi: 10.1007/s12223-014-0363-x.

49. Saeed ZK, Abbas BA, Othman RM. Molecular identification and phylogenetic analysis of lactic acid bacteria isolated from goat raw milk. Iraqi Journal of Veterinary Sciences, 2020; 34; (2), 259-263

\section{Figures}


A

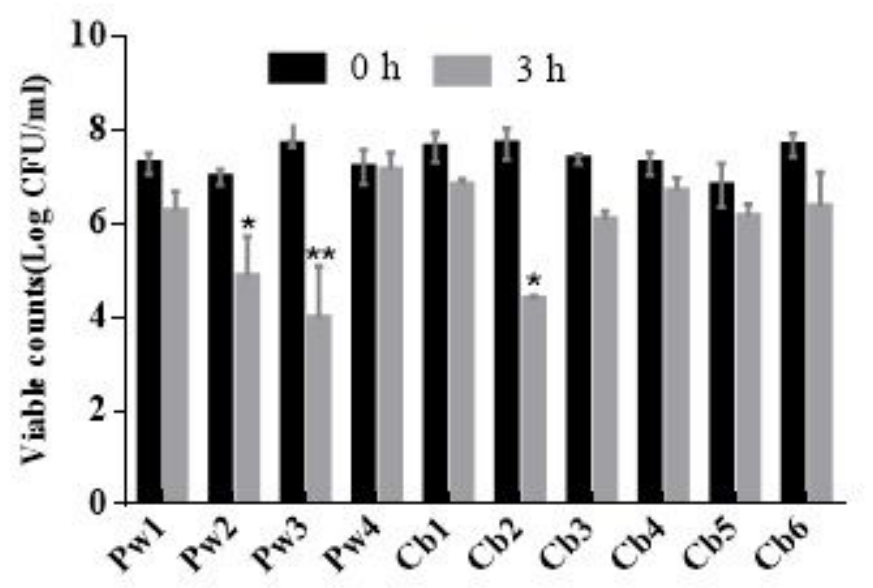

Isolates

B

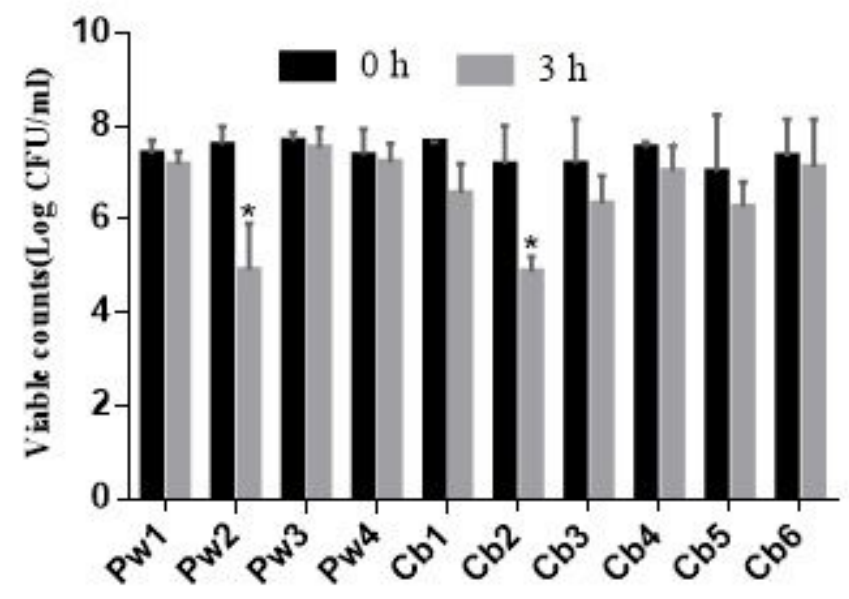

Isolates

Figure 1

Effect of $\mathrm{pH}$ on the growth of lactic acid bacteria strains. Colony forming units were counted at 0 and 3 hours at $(\mathrm{A}) \mathrm{pH} 2$, and $(\mathrm{B}) \mathrm{pH} 3$. Data are expressed as mean \pm standard deviation. * Significant differences at $p<0.05,{ }^{*} p<0.01$ 
A
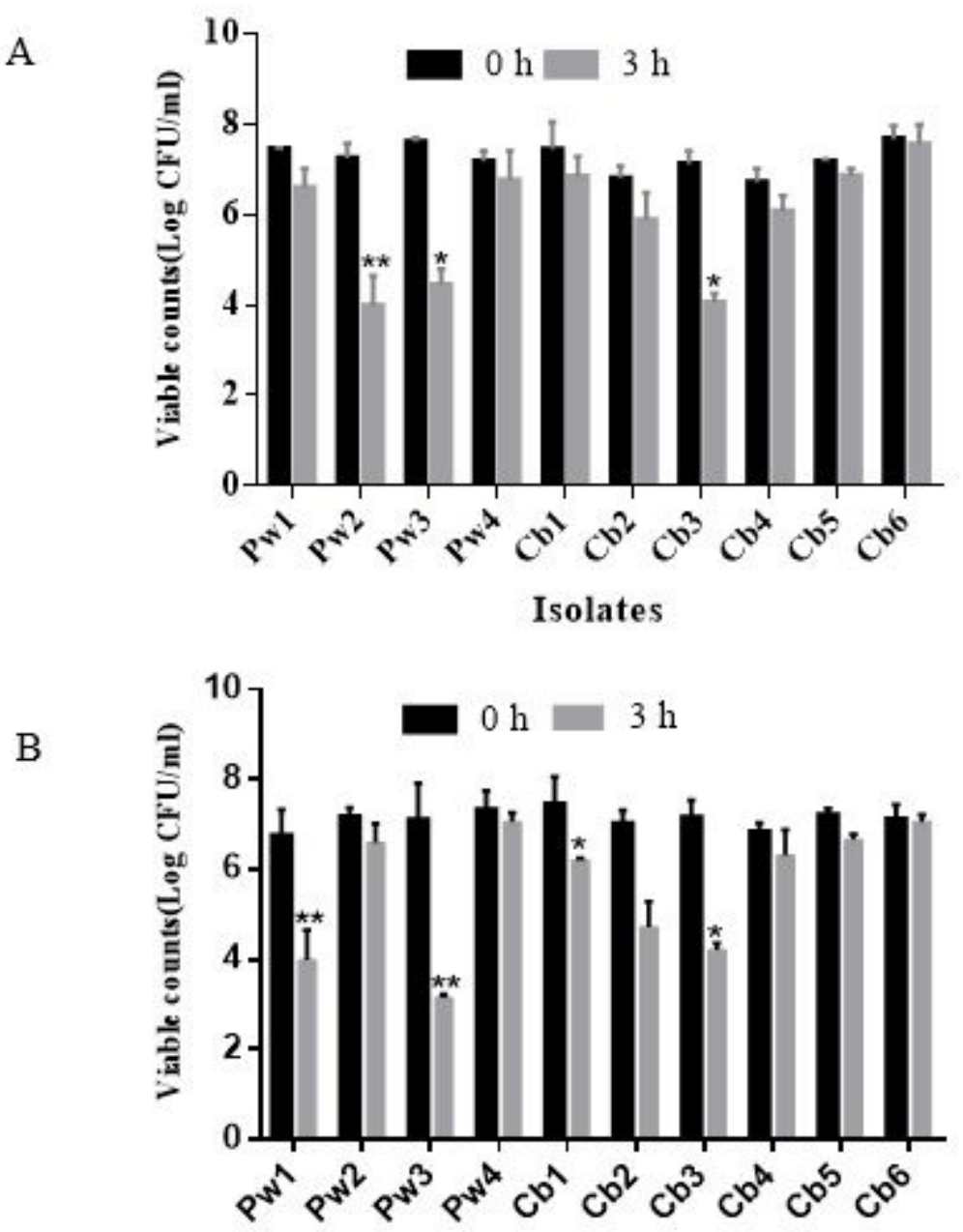

Isolates

Figure 2

Effect of bile salt concentration on the growth of lactic acid bacteria strains. Colony forming units were counted at 0 and 3 hours at different bile salt concentration; (A) $0.2 \%$, and (B) $0.4 \%$. Data are expressed as mean \pm standard deviation. * Significant differences at $p<0.05,{ }^{* *} p<0.01$

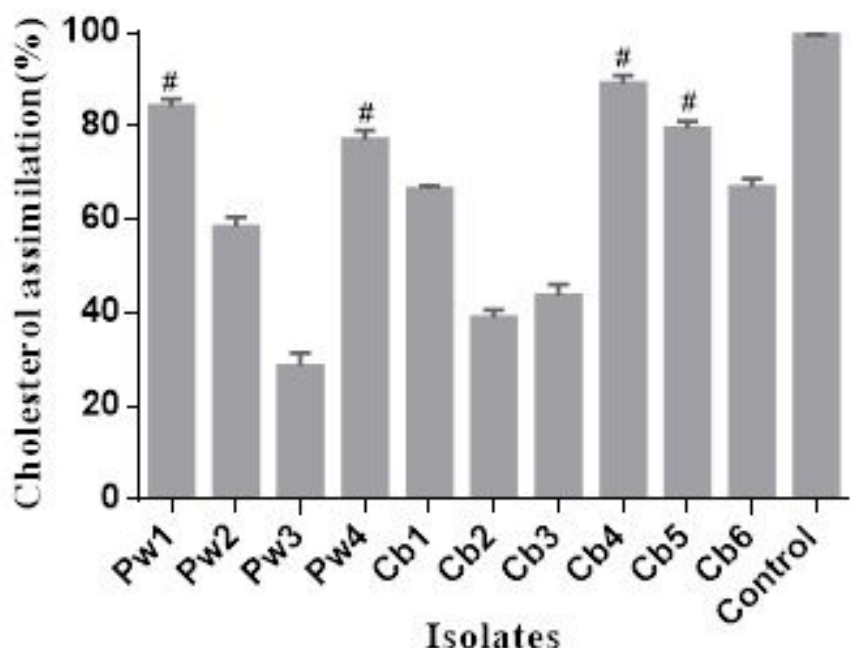




\section{Figure 3}

Cholesterol assimilation by LAB strains at $1 \%$ cholesterol and bile salt concentration of $0.4 \%$ for $24 \mathrm{~h}$. Data are expressed as mean \pm standard deviation. \# assimilated cholesterol $>75 \%$
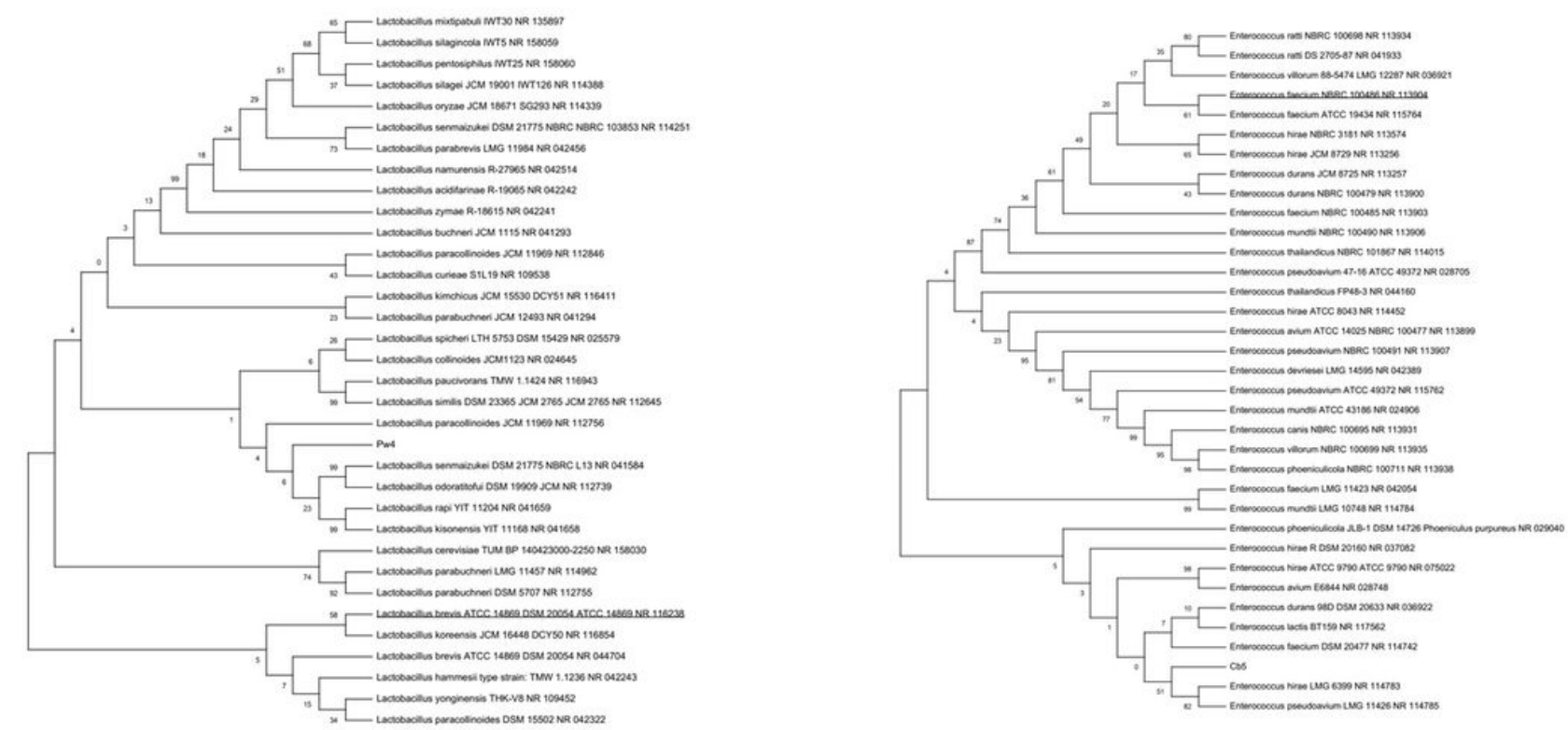

Figure 4

Phylogenetic tree constructed showing the position of isolate; (A) Pw4, (B) Cb5 and related Lactobacillus species. 